\title{
More alive than dead: non-apoptotic roles for caspases in neuronal development, plasticity and disease
}

\author{
Amrita Mukherjee ${ }^{1}$ and Darren W Williams ${ }^{\star, 1}$
}

Nervous systems are arguably the most fascinating and complex structures in the known universe. How they are built, changed by experience and then degenerate are some of the biggest questions in biology. Regressive phenomena, such as neuron pruning and programmed cell death, have a key role in the building and maintenance of the nervous systems. Both of these cellular mechanisms deploy the caspase family of protease enzymes. In this review, we highlight the non-apoptotic function of caspases during nervous system development, plasticity and disease, particularly focussing on their role in structural remodelling. We have classified pruning as either macropruning, where complete branches are removed, or micropruning, where individual synapses or dendritic spines are eliminated. Finally we discuss open questions and possible future directions within the field.

Cell Death and Differentiation (2017) 24, 1411-1421; doi:10.1038/cdd.2017.64; published online 23 June 2017

Facts

- Caspases have crucial non-death-related roles in neurons.

- Both macropruning and micropruning events deploy key components of the intrinsic caspase pathway.

- Caspases initiate micropruning events in progressive neurodegenerative diseases as the key proteins involved have emerged as caspase substrates.

\section{Open Questions}

- Are cytochrome $c$ or Apaf1 dispensable for nonapoptotic roles?

- Are effector caspases activated de novo or stalled and released upon non-apoptotic stimulus?

- What molecular mechanisms restrict the extent and spread of activated caspases?

- From an evolutionary perspective what came first-their use in killing or sculpting?

The nervous system is remarkable not just because of its cellular diversity and elaborate connectivity but also because its structure changes constantly throughout life: growing at first, remodelling from experiences, and then degenerating. Here we focus on the non-apoptotic roles that caspases have in the structural remodelling of neurons.

The size and complexity of neurons gives us an opportunity to explore the fundamental principles of cellular design. Some of the largest cells in the body are the motoneurons that innervate the adductor hallucis muscles in our foot. If the cell body of this class of motoneuron were the size of a Volkswagen Beetle then the axon would be equivalent to a
$40 \mathrm{~km}$ exhaust pipe. This great distance between the cell body and the distal compartments allows us to tease apart events that would otherwise be difficult to resolve in compact cells such as fibroblasts. The devolved nature of neurons encourages us to think differently about how caspase-based signals propagate.

\section{The Caspases}

Caspases are a highly conserved family of cysteine proteases found in all multicellular animals. Although key regulators of inflammation (reviewed in Jiménez Fernández and Lamkanfi ${ }^{1}$ ), they are best known for orchestrating apoptotic cell death during development, normal physiology and disease. Until recently, this 'executioner' role of caspases had obscured their non-apoptotic roles, which have now come into focus. Caspases are generated as pro-enzymes and become active after processing. They are best grouped by their function, as either initiator caspases (Dronc, Dredd and Strica in Drosophila and caspase-1, -2, $-4,-5,-8,-9,-10,-11$, -12 in mammals) or effector caspases (Drice, Dcp1, Decay and Damm in Drosophila and caspase-3, -6, -7 and -14 in mammals). Initiator caspases have long $\mathrm{N}$-terminal prodomains and exist as monomers. Upon dimerization, they act on a limited number of substrates, including the effector caspases. In contrast, effector caspases have short $\mathrm{N}$-terminal pro-domains, exist as inactive dimers and have hundreds of targets. Substrate specificity is determined by defined caspase cleavage sites found within target proteins. Depending on the interacting proteins and the initiator caspases involved, there are two main routes to caspase activation: The extrinsic and the intrinsic pathways, both of which converge on the effector, caspase-3.

\footnotetext{
${ }^{1}$ Centre for Developmental Neurobiology, King's College London, London, UK

*Corresponding author: DW Williams, Centre for Developmental Neurobiology, King's College London, New Hunt's House, 4th Floor, Guy's Hospital Campus, London SE1 1UL, UK. Tel: +44 (0)20 7848 6550; E-mail: darren.williams@kcl.ac.uk

Received 16.1.17; revised 31.3.17; accepted 03.4.17; Edited by Eli Arama; published online 23.6.17
} 
The key mediators in the extrinsic pathway are death receptors (DRs) that belong to the tumor necrosis factor receptor family. Ligand binding triggers receptor clustering and recruitment of adaptor proteins, which activate pro-caspases. For a review of the extrinsic pathway, see Elmore. ${ }^{2}$

The intrinsic pathway is triggered by mitochondrial outer membrane permeabilization (MOMP), which releases cytochrome $c$ (cyt-c). This allows the formation of the apoptosome, an oligomeric platform, containing cyt-c, apoptosis proteaseactivating factor-1 (Apaf1) and the initiator, Capsase-9. In mammals, MOMP is gated by the pore-forming proapoptotic $\mathrm{Bcl} 2$ family of proteins (e.g., Bax, Bak and $\mathrm{BH} 3$-only proteins) that are antagonized by the antiapoptotic members of the same family (e.g., Bcl-xL and $\mathrm{Bcl} 2$ ). Bax is predominantly cytoplasmic, translocating to the mitochondria upon apoptotic stimuli. Conformational changes in Bax and Bak allows homooligomerization and MOMP. The proapoptotic BH3-only proteins activate Bax/Bak directly or indirectly by inhibition of the antiapoptotic Bcl2 proteins (reviewed in Czabotar et al. ${ }^{3}$ ). Although cyt-c and Apaf1 are present in worms, flies and mammals, their requirement for apoptosome formation and caspase activation varies (reviewed in Kornbluth and White ${ }^{4}$ ). Activated initiator and effector caspases can be inhibited/ ubiquitylated by binding to the inhibitor of apoptosis (IAPs) via their BIR domains. ${ }^{5}$ This IAP-based inhibition is relieved by the IAP-binding motif (IBM) proteins Smac/Diablo and Omi/Htra2 in mammals or by Reaper, Hid and Grim in Drosophila that bind to IAP BIR domains via an IBM. ${ }^{6-9}$

\section{'I’m Not Dead!' — The Holy Grail}

The non-apoptotic role of caspases. The core apoptotic machinery was largely discovered in Caenorhabditis elegans, which dominated the field for a long time. The generation of mutants in Drosophila and subsequent in vivo studies revealed key non-apoptotic roles for caspases during development. The first non-death role was seen in spermatid individualization that required Dark (dApaf1), Dronc, Dcp1 and Hid. ${ }^{10,11}$ Around the same time Dronc, but not effector capsases, was found to be required for compensatory cell divisions in Drosophila wing discs. ${ }^{12-16}$ The first nonapoptotic role of caspases in fly nervous system was found in sensory organ precursor development, where Dronc was found to regulate Wingless signalling. ${ }^{17}$ Although caspases had been implicated in tissue remodelling (e.g., megakaryocytes) and axon growth for some time, ${ }^{18}$ the power of Drosophila genetics proved to be a 'watershed' for elucidating the non-apoptotic roles of caspases. Here we focus on how caspases sculpt postmitotic neurons. (for caspases in cellfate specification, see review Kuranaga and Miura ${ }^{19}$ ).

\section{Caspase Activation During Neuronal Remodelling}

Regressive phenomena are crucial for the matching of network components during development and later for circuit refinement. Pruning, the selective elimination of synapses, axons or dendrites, occurs without death of the parent neuron $^{20}$ and its dysregulation has been implicated in disorders, such as schizophrenia ${ }^{21}$ and autism. ${ }^{22}$ It has been defined as either small or large scale, depending on the size of branches removed. Pruning is absent from other organ systems and difficult to recapitulate in a dish, making it one of the least understood cell biological phenomena.

We classify pruning events here as being either macropruning or micropruning. Macropruning refers to removal of intact branches, be they large or small. This occurs either by distal to proximal branch retraction ${ }^{23}$ with axosome shedding ${ }^{24}$ as seen at the vertebrate neuromuscular junction or by a local degeneration, such as in thalamocortical projection neurons where branches are cut and the processes distal to the cut then fragment. $^{25}$ Micropruning events comprise of local structural changes in individual presynaptic boutons or dendritic spines. Most work has focussed on postsynaptic events, where dendritic spines shrink or are removed along a dendritic shaft. ${ }^{26,27}$

Insects undergoing complete metamorphosis are excellent models for macropruning as they possess large, identifiable neurons that predictably remodel. ${ }^{28}$ The advent of molecular labelling tools has allowed pruning to be visualized in the nervous systems of small creatures, such as Drosophila. ${ }^{29,30}$ Pioneering studies in Drosophila mushroom body $\gamma$-neurons revealed that axons and dendrites prune by local degeneration $^{31}$ similar to that in vertebrates. ${ }^{32,33}$ Live- $^{2}$ imaging of dendritic arborization (da) sensory neurons, particularly ddaC, the dorsal class IV da, gave unprecedented access to the cellular details of macropruning. ${ }^{34,35}$ In these sensory neurons, cytoskeletal changes result in thinning of proximal branches, branch severing, fragmentation and clearance of debris by phagocytosis ${ }^{34,36}$ (Figure 1). When these larval-specific dendrites are removed, adult-specific arborizations begin to regrow in their place.

In the mid-1990s, Raff et al. ${ }^{37}$ found no obvious role for caspases in nerve growth factor (NGF)-dependent degeneration of axons. Parallel in vivo studies on pmn mutant mice overexpressing $\mathrm{Bcl}-2$ suggested that caspases were not involved in dying-back degeneration. ${ }^{38}$ The inhibition of caspases in Drosophila $y$-neurons also showed no disruption during remodelling. ${ }^{31}$ Nevertheless, live-imaging and the 'apoptotic-like' features seen in da sensory neuron pruning ${ }^{34}$ prompted $\mathrm{us}^{39}$ and others ${ }^{40}$ to revisit this idea. Using a genetically encoded caspase probe expressed only in pruning neurons, we revealed active caspases within degenerating branches. $^{39}$ In addition, the initiator caspase Dronc, Dark (dApaf1), the DIAP1 (Drosophila IAP) along with Effete/UbcD1 and $\mathrm{VCP}^{40,41}$ were found to be required for pruning (see Table 1). The presence of active caspases and a requirement for components of the canonical apoptotic pathway during pruning provided strong evidence for caspases in non-apoptotic roles.

With this perspective and new genetic tools, the role of caspases in vertebrate axon remodelling was revisited. Using Campenot chambers and microfluidic devices, axon degeneration was reinvestigated with the NGF withdrawal paradigm. These in vitro approaches allow either cell bodies or the neurites to be independently exposed to different local environments (Figure 2). The role of various components of the apoptotic machinery were tested using pharmacological and knockdown approaches. ${ }^{42,43}$ A number of studies have used gene knockouts to confirm that caspase- 9 and caspase- 3 are essential for axonal 
a

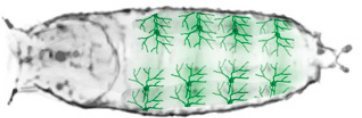

b

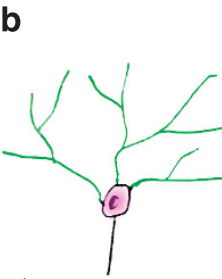

Oh APF
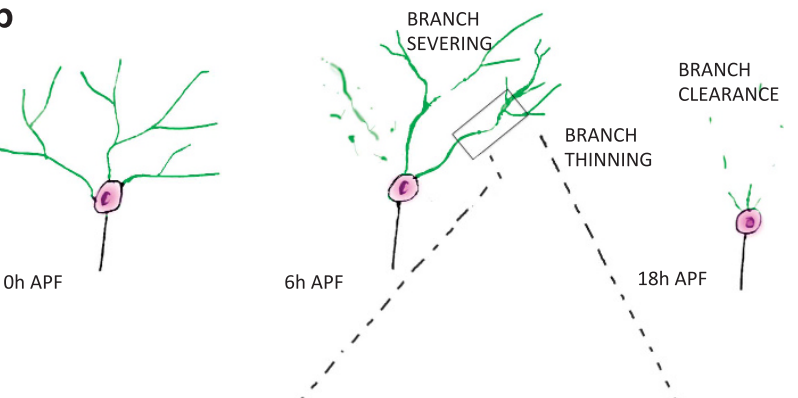

$$
6 \mathrm{~h} \mathrm{APF}
$$
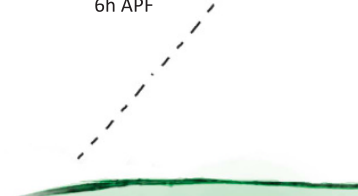

C

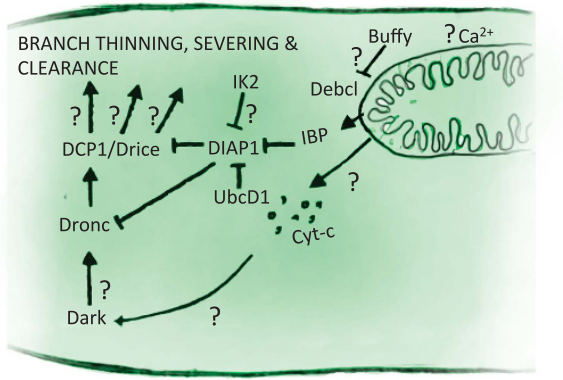

Figure 1 Non-apoptotic role of caspases in dendritic arborization neuron remodelling. (a) Overview of Drosophila white pre-pupae (grey) with abdominal dendritic arborization (da) sensory neurons in superficial position on dorsal body wall aspect (green). (b) Da sensory neurons undergo remodelling during early metamorphosis. Pruning starts with initial thinning of branches, followed by severing at $6 \mathrm{~h}$ after puparium formation (APF), and is completed with the clearance fragments of the severed branches by $18 \mathrm{~h}$ APF. (c) The apoptotic machinery involved in the pruning of da neurons includes Dark (dApaf1), the fly caspaseDronc, DIAP1 and its regulator $\mathrm{UbcD1}$. The question marks represent the current unknowns in the pathway. $\mathrm{Ca}^{2+}$, calcium ions; IBP, IAP-binding motif proteins; IK2, I $\kappa$ B kinase

pruning and find that caspase-6, BAX and $\mathrm{XIAP}^{44-47}$ are also involved. Many of these are also required for retinal ganglion cell (RGC) pruning, in vivo ${ }^{44}$ (see Table 1). An important point to note here is that in full mutants of the apoptotic pathway, the intact axons of 'undead neurons' might coexist alongside the 'unpruned' axons of remodelling cells, making interpretations difficult. Our work in Drosophila has demonstrated that neurons 'fated to die' do not always prune their processes by default. ${ }^{34}$ The non-apoptotic role of caspases in macropruning has had many peaks and troughs, but the new data strongly suggest many discoveries lie ahead on the horizon.

\section{Learning and Memory - Caspases in Synaptic Plasticity}

Connectivities established during development are not fixed and can be modified with experience. Such changes, largely taking place at the synapse, are termed synaptic plasticity and are currently considered the strongest candidate mechanism for the biological basis of learning and memory. Long-term potentiation (LTP) ${ }^{48}$ and long-term depression (LTD) $)^{49,50}$ are two of the most well-studied experimental forms of synaptic plasticity in mammals and are believed to model the effects of experience and deprivation on the nervous system. Out of several, the most celebrated form of glutamatergic synaptic plasticity is mediated by two postsynaptic ionotropic glutamate receptors: the NMDA and AMPA receptors. ${ }^{51}$ The NMDA receptor (NMDAR) is a core induction mechanism both for LTP and a form of LTD, serving as a coincidence detector of presynaptic and postsynaptic activity as it requires both ligand and voltage gating. A major expression of NMDAR-dependent LTD is a decrease in synaptic strength resulting from AMPA receptor (AMPAR) internalization at the postsynapse, ${ }^{52}$ with correlated structural change, shrinkage or loss, particularly in juvenile animals. ${ }^{53}$ Application of the agonist NMDA in culture induces a form of 'chemical LTD'54 resulting in AMPAR removal and micropruning, with dendritic spine shrinkage and loss. ${ }^{27,55}$ These structural changes are correlated with decreased responsiveness to neurotransmitters.

Mattson and colleagues first proposed active caspases as a driving force for LTD. ${ }^{56,57}$ Important support for the role of caspases in learning and memory came from the finding that AMPAR subunits are caspase substrates..$^{58}$ The physiological significance of caspases were first shown when active caspase-3 immunoreactivity was detected in the hippocampus of naive rats. ${ }^{59}$ The active caspase- 3 immunoreactivity could also be significantly decreased by injection of caspase inhibitors that resulted in changes to long-term spatial memory storage ${ }^{59}$ and active avoidance learning.$^{60}$ In hippocampal slices incubated with z-DEVD-FMK, a caspase inhibitor, LTP appeared to be suppressed; ${ }^{61}$ however, a later study using slices from caspase-3 knockout mice showed no change in LTP, yet LTD was suppressed. ${ }^{62}$ Elegant in vivo studies revealed the spatio-temporal dynamics of caspase-3 activation in the zebra finch during song response habituation. ${ }^{63}$ They found active caspase-3 in the dendritic spines 10-20 min after novel song exposure. Injection of caspase-3 inhibitor prior to song habituation blocked the appearance of persisting memory $24 \mathrm{~h}$ after a novel song. In this system, active caspases are bound to XIAP, suggesting that upon stimulation they are released quickly. ${ }^{63}$ Postsynaptic overexpression of $\mathrm{Bcl}-\mathrm{xL}$ and different fragments of XIAP also inhibited AMPAR internalization and suppressed LTD in rodents. ${ }^{62}$ NMDA treatment of cultured hippocampal neurons induced a rapid and transient increase in active caspase- 3 , and cyt-c levels peaked within 30 min of NMDA treatment before decreasing to baseline. This brief pulse of active caspase-3 did not result in cell death. ${ }^{62}$ Recently, a study using cultured hippocampal neurons from a XIAP knockout mouse showed reduced synapse number and increased AMPA internalization after NMDA treatment, ${ }^{64}$ providing compelling evidence that XIAP regulates sublethal levels of synaptic caspase-3 activity and has an important role in learning and memory formation. ${ }^{64}$ Support for mitochondrial pathway in NMDAR-dependent LTD was provided using siRNA knockdown and knockout of Bad and Bax in hippocampal slices, ${ }^{65}$ both of which also resulted in a decrease in AMPAR internalization when stimulated with NMDA. In CA1-specific Bax knockout mice, long-term contextual fear memory was impaired although acquisition of fear memory was unaffected. ${ }^{66}$ There is enough evidence to suggest that the role of caspases in micropruning events is critical, but still much about this rapid and fine-scale regulation remains to be understood (Figure 3 and see Table 1). 
Table 1 Table summarising the role of caspases and related molecules in dendrite pruning, axon remodelling and learning and memory

\begin{tabular}{|c|c|c|c|c|c|c|c|}
\hline & \multicolumn{7}{|c|}{ BCL2 FAMILY } \\
\hline & CYT- C & APAF1 & $\begin{array}{c}\text { PRO- } \\
\text { APOPTOTIC }\end{array}$ & $\begin{array}{c}\text { ANTI- } \\
\text { APOPTOTIC }\end{array}$ & $\begin{array}{l}\text { INHIBITOR OF } \\
\text { APOPTOSIS } \\
\text { (IAPS) }\end{array}$ & $\begin{array}{c}\text { OTHER } \\
\text { REGULATORS }\end{array}$ & CASPASES \\
\hline $\begin{array}{l}\text { MACRO- } \\
\text { PRUNING }\end{array}$ & Released? & $\begin{array}{c}\text { Dark/Dapaf1 } \\
\text { (D.m) [39] }\end{array}$ & Not known & Not known & DIAP1 & UbcD1, VCP & Dronc \\
\hline Dendrites & $\begin{array}{l}\text { Required? } \\
\text { (D.m) }\end{array}$ & & (D.m) & (D.m) & (D.m) $[39,40]$ & $\begin{array}{c}\text { (D.m) }[40, \\
41]\end{array}$ & (D.m) $[39,40]$ \\
\hline 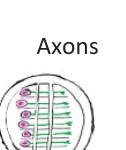 & $\begin{array}{l}\text { Released. } \\
\text { Required? } \\
\text { (SCG) [45] }\end{array}$ & $\begin{array}{l}\text { Not required } \\
\text { (SCG) [45] } \\
\text { Required [47] }\end{array}$ & $\begin{array}{c}\text { Bax (SCG) } \\
\text { [45]; (DRG) } \\
{[44]}\end{array}$ & $\begin{array}{c}\mathrm{Bcl} 2, \mathrm{Bcl}-\mathrm{xL}, \\
\mathrm{Bclw}(\mathrm{DRG}) \\
{[44]}\end{array}$ & $\begin{array}{c}\text { X-IAP (SCG) [45]; } \\
\text { (DRG) [46] }\end{array}$ & $\begin{array}{c}\text { FAIM-L (DRG) } \\
{[120]}\end{array}$ & $\begin{array}{c}\text { Caspase-6, } \\
\text { Caspase-3, } \\
\text { Caspase-9 (SCG) } \\
{[45] ; \text { (DRG) }[44,46]}\end{array}$ \\
\hline $\begin{array}{l}\text { MICRO- } \\
\text { PRUNING }\end{array}$ & $\begin{array}{c}\text { Released. } \\
\text { Required? } \\
\text { [62] }\end{array}$ & Not known & $\begin{array}{c}\text { Bad, Bax } \\
\text { (LTD mice) } \\
{[65]} \\
\text { (memory } \\
\text { mice) [66] }\end{array}$ & $\begin{array}{c}\text { Bcl-xL (LTD } \\
\text { mice)[62] }\end{array}$ & $\begin{array}{c}\text { X-IAP (LTD mice) } \\
\text { [62], (learning \& } \\
\text { memory mice) } \\
\text { [64], (learning \& } \\
\text { memory zebra } \\
\text { finch) [63] }\end{array}$ & $\begin{array}{l}\text { FAIM-L (LTD } \\
\text { mice) [120] }\end{array}$ & $\begin{array}{c}\text { Caspase-9,-3 (LTD } \\
\text { rat) [62], (memory } \\
\text { rat)[59],(active } \\
\text { avoidance } \\
\text { learning) [60] } \\
\text { (memory zebra } \\
\text { finch) [63] }\end{array}$ \\
\hline
\end{tabular}

Abbreviations: CYT-C, cytochrome $c$; dApaf1, Drosophila apoptotic protease-activating factor 1; DIAP1, Drosophila inhibitor of apoptosis 1; D.m, Drosophila melanogaster, DRG, dorsal root ganglion; FAIM-L, Fas apoptotic inhibitory molecule protein long form; LTD, long-term depression; SCG, superior cervical ganglion; VCP, Valosin containing protein; X-IAP, X-linked inhibitor of apoptosis protein. References for evidence for the molecules involved are mentioned

\section{Capsase Activation During Progressive Neurological Disease}

In the mature and aging nervous system, active caspases are a double-edged blade. The ultimate fate of neurons in progressive neurological disorders is death and caspases are deployed for this function. However, the majority of chronic neurological disorders are fundamentally disorders of the synapses and caspases can often have the not so obvious role of initiators of the degenerative process. Here we focus on the role of caspases in Alzheimer's and Huntington's disease ( $A D$ and $H D$, respectively) prior to neuronal cell death.

Alzheimer's disease. $A D$ is a neurodegenerative disorder with progressive cognitive decline and memory loss that correlates with dysregulation of early synaptic function and decreased spine density in the AD brain. ${ }^{67}$ The presence of active caspases before evidence of neurofibrillary tangles in tau overexpression mouse models ${ }^{68,69}$ and increased active caspase-3 corresponding with memory decline in an $A D$ mouse Tg2576 before detection of plaques ${ }^{70}$ suggests nondeath-related roles of caspases in $A D$ pathogenesis.

Amyloid precursor protein (APP), one of the key proteins in AD pathogenesis, is alternatively spliced and processed by caspases and other enzymes, releasing four proapoptotic peptides, including $A \beta$ and $C 31 .{ }^{71}$ Intra-hippocampal inhibition of $\gamma$-secretase suggested $A \beta$ is important for AMPAR internalization and the structure of dendritic spines. ${ }^{70}$ Interestingly, $A \beta$ also causes preferential endocytosis of synaptic NMDAR, ${ }^{72}$ thus disturbing the synaptic/extrasynaptic NMDAR balance, subsequently reducing pro-survival signalling. ${ }^{73}$ In addition to enhancing LTD, A $\beta$ oligomers also inhibit LTP by activating caspase-3, which cleaves Akt, releasing tonic inhibition of kinase GSK3 $\beta .^{74}$ Although excessive $A \beta$ is neurotoxic, at picomolar concentrations it enhances LTP and memory formation, ${ }^{75,76}$ suggesting a native role. In an Apaf1 null background, Tg2576 mice did not activate caspase-3, suggesting involvement of the mitochondrial pathway. ${ }^{70}$ Other caspases, such as caspase- 6 and the ER-resident caspase- 4 are also associated with $A D,,^{77,78}$ and activation of the ER stress pathway was observed in vivo and in vitro. ${ }^{79,80}$ Proteomics approaches have revealed that caspase- 6 substrates include cytoskeletal proteins and others associated with learning and memory, ${ }^{81}$ but a direct evidence of caspase -4 and -6 action in synapses is currently lacking. Caspase-3, -6 or -8 can cleave APP, generating the C31 fragment, whose toxicity depends on its interaction with APP itself. ${ }^{82}$ C31 acts as a potent inducer of apoptosis, ${ }^{83}$ possibly by inhibiting XIAP via an N-term Smac/Diablo-like motif. ${ }^{84}$ Activation of caspases or increased calcium levels upon deposition of $A \beta^{85}$ activates calcineurin-mediated dephosphorylation and internalization of AMPARs. Similar to caspase-3-mediated LTD, activation of GSK3 $\beta$ via Akt cleavage may also contribute to AMPAR internalization in AD (Figure 3). GSK3 $\beta$ can hyperphosphorylate tau, another known caspase- 3 substrate. ${ }^{86}$ Caspase activation by soluble $A \beta$ thus sets off a feedback loop generating more active caspases and toxic protein fragments that can dysregulate and destroy synapses long before neuron death. 
a

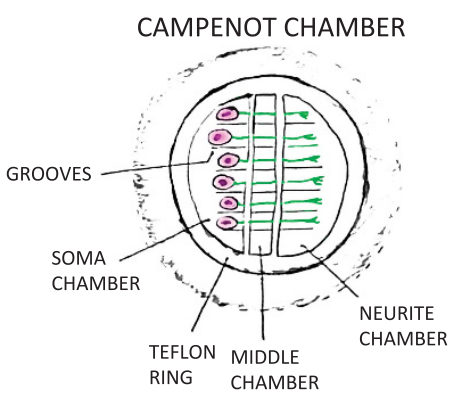

$\begin{array}{ccl}\text { b } & \text { SOMA } & \text { NEURITE } \\ & \text { CHAMBER } & \text { CHAMBER }\end{array}$

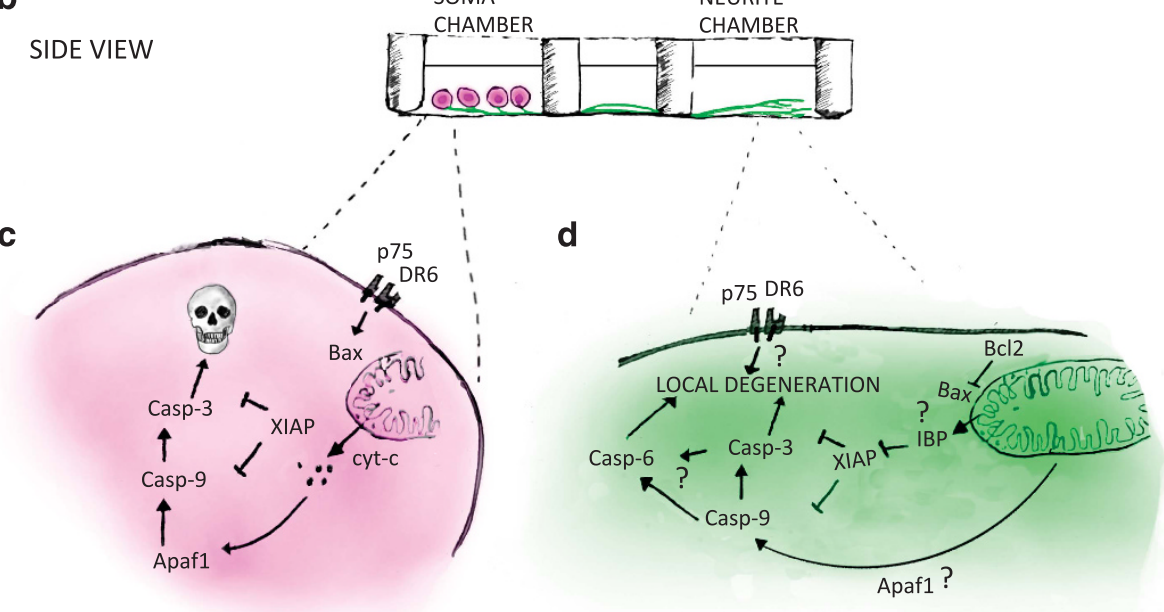

GLOBAL NGF WITHDRAWL

LOCAL NGF WITHDRAWL

Figure 2 Non-apoptotic role of caspases in NGF-dependent axon degeneration. Axon degeneration and pruning can be studied using a Campenot chamber ((a) top view and (b) side view). The chamber separates the soma (magenta) and neurite (green) chambers so that cells can be manipulated to either globally or locally deprive neurons of growth factor (NGF). Global withdrawal that results in neuron death (c) does not require Caspase-6, which is important for (d) local NGF withdrawal-induced axonal pruning. The role of IAP-binding motif proteins (IBPs), Bax, XIAP and Caspases-9, -3 and -6 have all been shown to regulate local NGF-induced axonal pruning. The activation of the pro-caspase 9 without Apaf1 and the mechanism of caspase-6 activation require further investigation. Current unknowns are represented by the question marks. DR, death receptor $6 ; p 75, p 75$ neurotrophin receptor; IBP, IAP-binding proteins; Casp-9, caspase-9; Casp-3, caspase-3; Apaf-1, apoptotic protease-activating factor 1; XIAP, inhibitor of apoptosis 1 on X; Bax, BCL2-associated X; Bcl2, B-cell lymphoma 2 protein

Huntington's disease. HD is an inherited disease with progressive neuronal damage resulting in cognitive, behavioral and movement dysfunction. It is caused by an abnormal expansion of a trinucleotide repeat coding for Glutamine (Q) in the huntingtin ( $h t t)$ gene, and caspase- 6 is emerging as the key caspase in HD pathogenesis. ${ }^{87}$ Caspase-3 and -6 can cleave $\mathrm{Htt}$ to release the $\mathrm{N}$-terminal poly- $\mathrm{Q}$ tract, whose toxicity depends on the length of the poly- $Q$ and its nuclear localization, ${ }^{88-90}$ which can cause transcriptional upregulation of caspase-1. ${ }^{91}$ Cognitive deficits with defects in synaptic plasticity are an early symptom of $\mathrm{HD},{ }^{92}$ also observed in mouse models. ${ }^{93-95} \mathrm{mHtt}$ caused dendritic spine loss and impaired normal experience-dependent synaptic plasticity in a R6/2 HD mouse model. ${ }^{96} \mathrm{WtH} t \mathrm{tt}$ is known to be anti-apoptotic, ${ }^{97,98}$ but whether the presence of $\mathrm{mHtt}$ directly impacts caspases requires further investigation.

Thus, in addition to acting as substrates for caspases, key proteins in neurodegenerative diseases can also activate caspases causing a 'snowball' effect. The recent findings highlight that the non-apoptotic roles that caspases have as initiators of synapse loss, maybe far more important than their role as final mediators of cell death as they provide a target for therapeutic intervention before neuronal loss.

\section{Regulatory Mechanisms - What's the Same, What's Different?}

During structural remodelling, neurons need to deploy caspases while maintaining them at sublethal levels. Here we discuss some of the mechanisms that are known to regulate caspases during cell death and speculate on how these may be exploited for non-apoptotic roles.

Setting the basal levels. Precise in vivo manipulations of effector caspase expression in Drosophila have shown that the abundance of pro-caspases is directly proportional to caspase activity level, ${ }^{99}$ suggesting the existence of a 'threshold of activity' that induces apoptosis. Our recent data show different active effector caspase levels in remodelling neurons versus those destined to die during metamorphosis (Mukherjee and Williams, unpublished observations). It is possible that a cell's identity and age determines its capacity to generate different levels of caspase activity. 
a

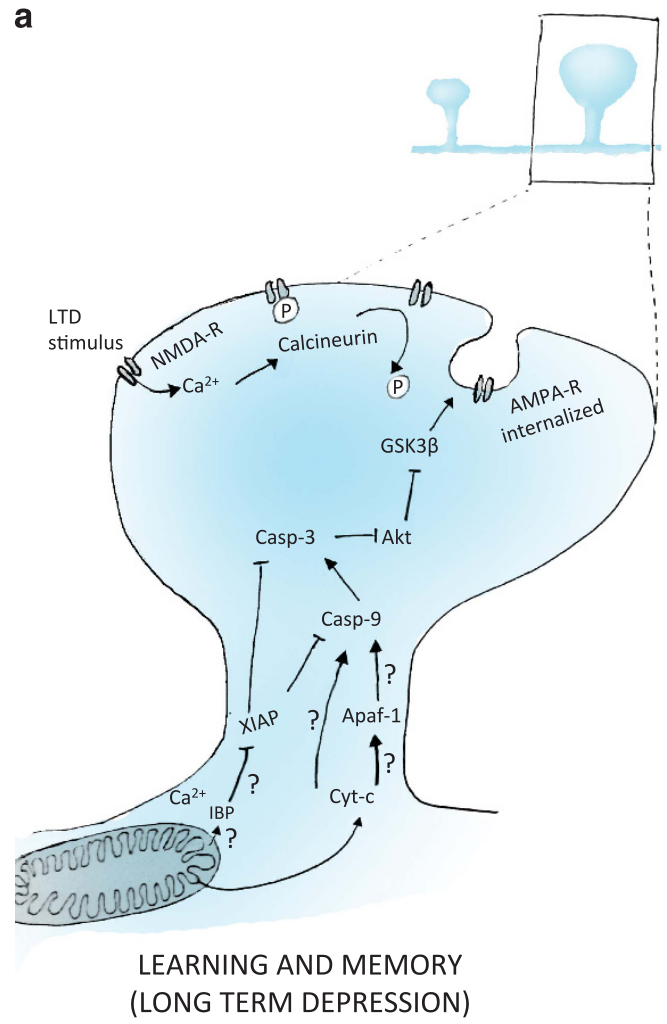

b

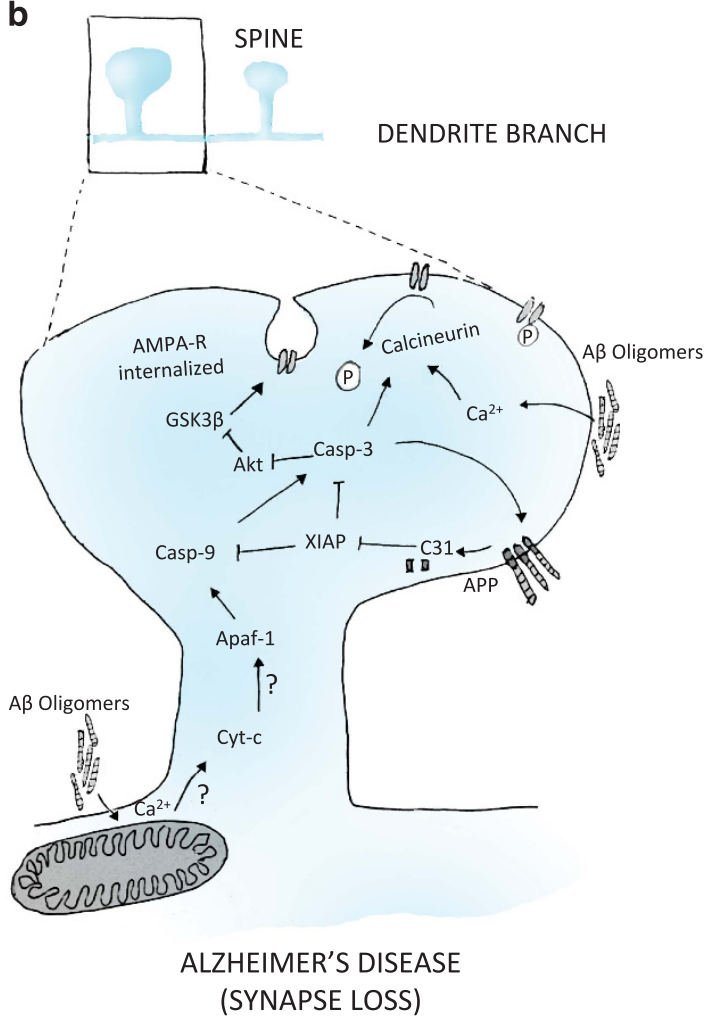

Figure 3 Non-apoptotic roles of caspases in micropruning in plasticity and disease. (a) Caspases-9 and -3 along with XIAP, Bad, Bax and antiapoptotic Bcl2 has been shown to be involved in NMDA-R dependent AMPA-R internalization. Active caspase cleaves Akt to release the inhibition of GSK3 $\beta$ and LTD. Although cyt-c is released, whether it is required for Apaf1 function and whether the IBM proteins are needed, require clarification. (b) In Alzheimer's disease (AD) presence of $\mathrm{A} \beta$ oligomers increases intrasynaptic $\mathrm{Ca}^{2+}$ levels to trigger caspase activation. C31 fragment derived from caspase cleavage and enzymatic processing of APP can block XIAP and further contribute to accumulation of active caspases. The requirement of cytochrome $\mathrm{c}$ and Apaf1 in the presence of $\mathrm{A} \beta$ oligomers is not known. This initial micropruning event can snowball into synaptic loss or dendritic branch loss and contribute to AD. The unknowns are represented by question marks. IBP, IAP binding motif proteins; $\mathrm{Ca}^{2+}$, calcium ions; Casp-9, caspase-9; Casp-3, caspase-3; Apaf-1, apoptotic protease activating factor 1; XIAP, inhibitor of apoptosis 1 on X; A $\beta$ oligomers, amyloid beta oligomers; Akt, protein kinase B; GSK-3, glycogen synthase kinase 3; AMPA-R, AMPA receptor; NMDA-R, NMDA receptor; C31, C31 fragment of the amyloid precursor protein; LTD, long-term depression; APP, amyloid precursor protein

One means to regulate the abundance of the core machineries of the apoptotic pathway is via transcription. Pruning in insects is controlled by developmental hormones that signal through the ecdysone receptor $\mathrm{EcR} / \mathrm{USP}^{30}$ with downstream targets such as transcription factor Sox-14. ${ }^{100}$ Both Dronc and Drice expression is regulated by steroid hormones via the transcription factor Broad-Complex $(B R-C){ }^{101,102}$ A Dronc promoter fragment showed dynamic levels of expression in the developing nervous system and other tissues. ${ }^{103}$ Interestingly, blocking effector caspases and death in imaginal disc cells maintained high levels of Dronc transcription ${ }^{104}$ suggesting a feedback signal, the mechanism of which remains unknown. Studies on neuronal cell death in vertebrates have mainly focussed on the apoptotic machinery in developing and not mature neurons, which tend to have different response to injury-induced death. ${ }^{105}$ In mature sympathetic neurons, repressive chromatin around the Apaf-1 promoter renders it inactive ${ }^{106}$ and an increased $\mathrm{Bcl} 2$ to Bax ratio ${ }^{107}$ likely provides that increased protection from death. It is not known whether caspase activation and regulation in non-apoptotic contexts also differ with a neuron's age. Recent work in DRG neurons in mammals suggested that transcription of PUMA, a member of the BH3-only subgroup, may activate caspases during axon degeneration. ${ }^{47}$ How this is achieved without the destruction of the soma compartment is an open question.

Studies in Drosophila also revealed that the levels of core apoptosome components can be controlled by post-translational inhibitory feedback mechanisms. When the levels of dApaf1 are artificially increased, the levels of Dronc are lowered and vice versa, which depends upon Dronc's caspase recruitment domain and a caspase cleavage site within dApaf1. ${ }^{108}$ Another post-translational mechanism involves de-ubiquitylating enzymes such as DUBA, which stabilizes Dronc, for example, in spermatid individualization in Drosophila. ${ }^{109}$ In vertebrates, two different caspase-9 transcripts are generated, one with proapoptotic and the other with antiapoptotic functions. Phosphorylation of caspase-9 also results in reduced activation and/or cleavage of itself. ${ }^{110}$ Although the majority of these mechanisms have been observed in dying cells, they may be deployed to regulate caspase levels in non-apoptotic functions.

Gating caspases in pruning. The timescale of macropruning events are similar to cell death, showing peaks in active caspases, lasting anywhere between an hour to a day. In 
contrast, the morphological changes in cortical neurons following low frequency stimulation reveal that spines can undergo shrinkage/micropruning within 30-60 min following induction. ${ }^{27}$ Similarly, rapid generation of active caspases following novel song stimuli in zebra finches was detected within 10 min. ${ }^{63}$ How are non-apoptotic caspases gated in these two different scenarios? Most of the data suggests involvement of mitochondria, and a number of possibilities exists through which the mitochondrial pathway could be activated. We postulate that one mode is a 'direct drive' system, where cyt-c is released with apoptosome formation while the other is through an IAP-based 'clutch' system with the active caspases stalled, ready for quick release upon stimuli, bypassing the need for Apaf1 and apoptosome formation (Figure 4).

There seems to be a discrepancy in the requirement of Apaf1 in NGF-dependent axon degeneration, ${ }^{45,47}$ but whether this arises due to differences in measurement, cell type or mutant backgrounds is unclear. Although more work is needed to address this, it will be useful to establish the requirement of Apaf1 in vivo in RGC axon pruning. In flies, dApaf- 1 is required for dendrite pruning, yet a direct role of mitochondria and MOMP in Drosophila apoptosis is still somewhat controversial. In addition, it is not known whether Apaf1 is required for LTD.

IAPs can bind directly to caspases or ubiquitylate them, either changing their function or targeting them for destruction via the proteasome. ${ }^{5,104,111}$ In vertebrates, XIAP is a key IAP that directly binds and inhibits active caspases but clAP1 can also bind and interact with processed and oligomerized caspase- 9 in the apoptosome to block procaspase-3 activation. ${ }^{112}$ Whether clAP is involved in non-apoptotic caspase functions requires investigation. In Drosophila programmed cell death, DIAP1 blocks Dronc activation without targeting it to the proteasome. ${ }^{104}$ Although DIAP1 is important for ddaC neuron pruning, ${ }^{40}$ its exact role remains an open question.

In zebra finch memory formation, active caspase-3 co-localizes and co-precipitates with XIAP. Active caspases can bind reversibly to IAPs. ${ }^{113,114}$ It is possible that, upon LTD stimulation, a brief loss of XIAP inhibition releases active caspase-3, sufficient to induce LTD and memory but not apoptosis. ${ }^{63}$ The quick and low-level activation of caspases in micropruning suggests that active caspases are likely to be stalled in some complex ready for release upon stimulation. In mammals, XIAP also inhibits the local degeneration of axons following NGF withdrawal. Currently, it is not clear whether such an IAP-based 'clutch' system is operating at the level of initiators or effectors or both (Figure 4).

In flies, IAPs are major regulators of the cell death through the complex spatial and temporal expression of the IAP antagonists - the IBM proteins (Reaper, Hid, Grim and Sickle) but it is not known whether they are required during Drosophila dendrite pruning. Are the analogous IBM proteins Smac/ Diablo and Omi/Htra2 in mammals controlling an IAP-based clutch for non-apoptotic events? Studies in HeLa cells reveal that while cyt-c is released within $5 \mathrm{~min}$, release of Smac take at least 20 min using similar assay. ${ }^{115}$ Although others have suggested a co-release of cyt-c and Smac, ${ }^{116,117}$ it may differ in different circumstances. For example, in non-apoptotic situations, an 'incomplete MOMP' or very low levels of Apaf1 may allow a sublethal caspase activation that does not result in death.

Bax is required in micropruning but its translocation to the mitochondria was not observed, in spite of cyt-c release. ${ }^{65}$ Interestingly, Bax-deficient human prostate cancer cells released Smac and cyt-c in response to apoptotic stimuli, ${ }^{117}$ thus suggesting that Bax may not be essential for MOMP. In

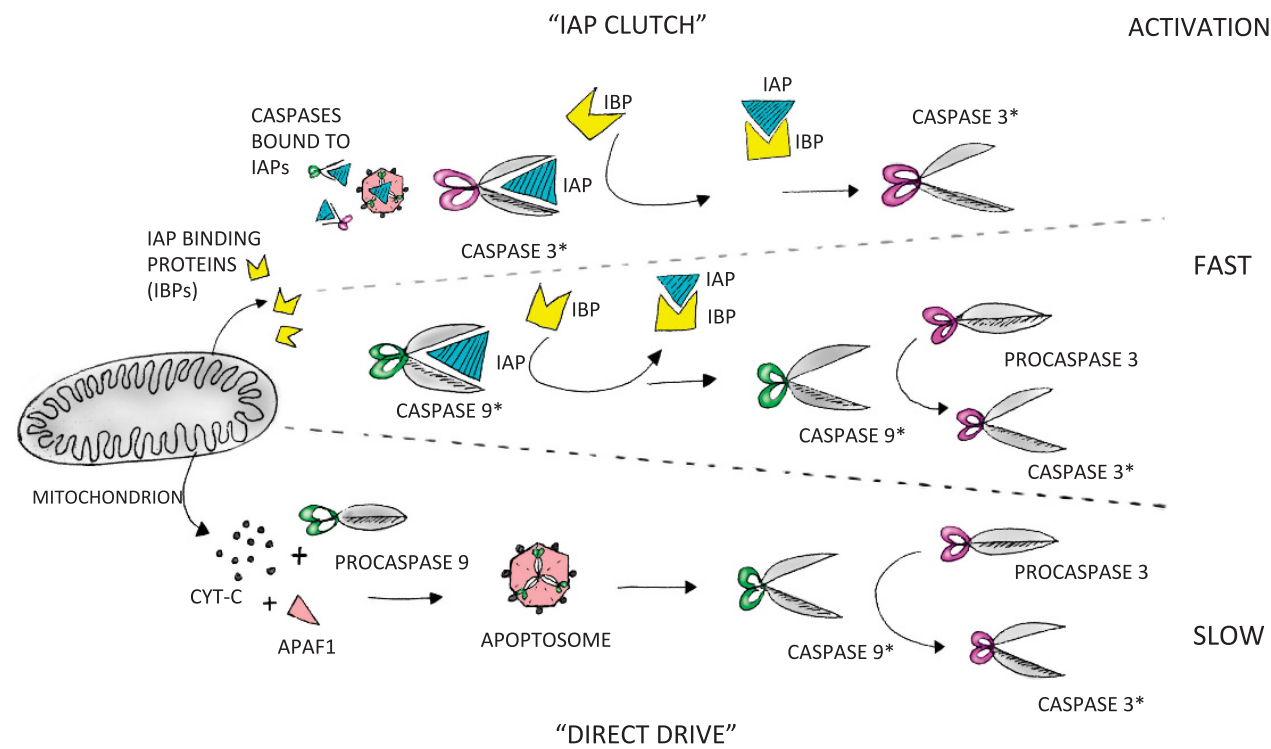

Figure 4 A speculative model of caspase activation in non-apoptotic roles. IAPs could be bound to ProCaspase-9/apotosome complex, activated Caspase-9 and/or activated Caspase-3. The transient and fast activation of caspases in non-apoptotic roles suggests a clutch-like role of IAPs where active caspases are stalled ready to be released and used. In 'direct drive' mode, the formation of the apoptosome might overwhelm the IAP clutch and push the system into a slow but more extensive accumulation of active caspases. caspase-3*, activated caspase-3; caspase-9*, activated caspase-9; APAF-1, apoptotic protease-activating factor 1; IAP, inhibitors of apoptosis; IBP, IAP-binding motif proteins 
non-apoptotic situations that require quick and modest caspase activation, a mechanism of Smac release bypassing Bax translocation could potentially inhibit IAPs briefly and quickly. Although several interesting possibilities exist, the role of mitochondria and the release of IBM proteins need further exploration in different model systems. Currently, it is also unknown whether Smac/Diablo and Htra2 are required for LTD and NGF withdrawal-dependent pruning.

Once caspases are active, IAPs may become crucial to prevent progression into apoptosis. Stabilization of the IAPs may therefore ensure activated caspases are kept at bay. The long form of Fas apoptosis inhibitory molecule (FAIM-L) has an IBM that prevents XIAP auto-ubiquitylation, maintaining its stability. ${ }^{118}$ FAIM-L is almost exclusively expressed in neurons ${ }^{119}$ and has recently been demonstrated to have a role in LTD and in NGF withdrawal-induced axonal degeneration by binding to and stabilizing XIAP. ${ }^{120}$

Overall, the intersection of these data strongly suggest that an IAP-based clutch could be important for controlling activation in a non-apoptotic context in both macropruning and micropruning. Future experiments looking at the dynamics of this in vivo will help us gain a clearer picture of the role of IAPs.

Localization of caspase action. Our previous work has shown that active caspases are restricted to the dendrites of the ddaC neurons ${ }^{39}$ similar to the immuno-EM data of activated caspase- 3 in the zebra finch, ${ }^{63}$ suggesting a localized activity. For non-apoptotic roles, if active caspases are to be 'available on demand', where are these active caspases maintained ready to be used? Subcellular localization of active caspases in granular structures has been observed in terminally differentiating cells, such as epithelial cells and megakaryocytes. ${ }^{121,122}$ Whether such granules exist in pruning events is unknown.

In most cells, caspase pro-enzymes are distributed in the cytoplasm while proapoptotic factors are localized in the mitochondria, ${ }^{123}$ which could also be important for keeping the active caspases local. Movement of mitochondria into active synapses during synaptic stimulation has been reported. ${ }^{124}$ The greater spread of LTD from the vicinity of the original stimulus (heterosynaptic LTD $^{125}$ ) as compared with LTP is also correlated with the presence of mitochondria across multiple postsynaptic sites. If mitochondria are important in restricting sublethal capase action, it would be interesting to follow up the work of Ertürk et al. (2014) and move mitochondria into and out of spines, while monitoring the local capsase activation. ${ }^{126}$ The proteasome machinery can also restrict active capsase-3 to the spines. ${ }^{126}$ In Drosophila, the UPS and proteasome have been found to be important in mushroom body $\gamma$ neurons ${ }^{31}$ and ddaC sensory neuron pruning. ${ }^{35}$ Alternatively, the local activity of caspases within branches could also be generated by a local inhibition mechanism at the soma, as seen with Tango and Bruce in developing sperm in Drosophila. ${ }^{127,128}$ As yet, it is not known whether these molecules have any role in neuronal pruning.

\section{'The Future ain't What it Used to be' - Yogi Berra}

The structural remodelling of neurons is a universal phenomenon within nervous systems. A question that emerges from the data is the extent of overlap that exists in the molecular mechanisms that orchestrate macropruning and micropruning events. In the context of caspase activation, the timescales appear to be very different; the rapid release of active caspase-3 in micropruning events suggest it is controlled by an IAP-based 'clutch'-like mechanism while macropruning can involve transcription and a step-wise activation of caspase-3 via apoptosome formation, that is, more similar to the classical apoptotic cascade (Figure 4).

In order to understand the overlap between caspasemediated micropruning and macropruning, we should look at the common substrates targeted by effector caspases in both cases. Activated effectors potentially cleave $>500$ target proteins in humans. ${ }^{129}$ Currently, little is known about caspase targets in non-apoptotic contexts. Structural changes in neurons, both large and small, are the result of cytoskeletal changes, making the cytoskeleton and its regulators some of the most likely candidates. In axon branches, caspase cleaved actin and tubulin fragments are detected locally with epitopespecific antibodies. ${ }^{130}$ However, in case of ddaC sensory neurons, the identity of caspase targets remain unknown.

So far, caspases do not seem to have a role in mushroom body $\gamma$ neuron remodelling. Is this due to the limitation of the tools used or are there parallel caspase-independent programmes of pruning? Surprisingly, active caspases have been found in the axon terminals in the RGCs during their elaboration phase and seem to have a non-destructive role in branch stabilization. ${ }^{131}$ Could these roles be more widespread than we realize? Unlike kinase/phosphatase pathways, protease signalling is an irreversible cleavage-based signal enabling the rapid and simultaneous inhibition or activation of diverse pathways. With multiple nodes at which inputs can exchange information, it should not be surprising that this machinery is used in so many contexts other than death. ${ }^{132}$

Another question that emerges from these observations is whether these non-death roles are ancient or more recent modifications to death programmes? To gain perspective on this, it would be useful to compare molecular mechanisms in a greater number of taxa. Does the emergence of non-apoptotic roles depend on the expansion of regulators and having multiple alternate ways of controlling the pathway? As Drosophila and $C$. elegans are representatives of the Ecdysozoa, it will be important to gather more information about caspase regulation in the other major Protostome clade, the Lophotrochozoa. Mapping the distribution of caspase targets, within complex tissues/cells that exhibit non-apoptotic processes in different groups, will give insights into evolution of this biology.

One other type of 'neuritic remodelling' is Wallerian degeneration. This evolutionarily conserved programme of neurite auto-destruction was revealed upon discovery of the Wids mouse and the Wids fusion protein. ${ }^{133,134}$ Loss-offunction studies in flies and mice revealed native 'Wldssensitive' machineries. ${ }^{135}$ Although interaction of the Wids machinery with caspase-dependent pruning has been 
explored, ${ }^{136}$ more work is needed to understand exactly how these two pathways interface.

Technological innovations will have a major impact on this field in the following years. CRISPR-Cas9 genome editing technology has already facilitated the generation of conditional alleles and multiple gene knockouts and the exploration of caspase biology in non-model organisms is not far away. High-resolution probes and optogenetic techniques will provide insights into the fine spatiotemporal activity of caspases while these new methods for perturbation will help speed discovery.

Thus time is ripe for exploring the cellular, molecular and evolutionary aspects of non-apoptotic caspase function. As we learn more about how these mechanisms construct, modify and ultimately disassemble our nervous system, it is likely that caspases will become as important to the living as they are to the dying and the dead.

\section{Conflict of Interest}

The authors declare no conflict of interest.

Acknowledgements. We thank $\mathrm{Dr}$ Samuel Cooke for his very helpful comments and Dr Elizabeth Marin for reading the manuscript.

1. Jiménez Fernández D, Lamkanfi M. Inflammatory caspases: key regulators of inflammation and cell death. Biol Chem 2015; 396: 193-203.

2. Elmore S. Apoptosis: a review of programmed cell death. Toxicol Pathol 2007; 35: 495-516.

3. Czabotar PE, Lessene G, Strasser A, Adams JM. Control of apoptosis by the BCL-2 protein family: implications for physiology and therapy. Nat Rev Mol Cell Biol 2014; 15: 49-63.

4. Kornbluth S, White K. Apoptosis in Drosophila: neither fish nor fowl (nor man, nor worm). J Cell Sci 2005; 118: 1779-1787.

5. Suzuki Y, Nakabayashi $Y$, Takahashi R. Ubiquitin-protein ligase activity of $X$-linked inhibitor of apoptosis protein promotes proteasomal degradation of caspase- 3 and enhances its anti-apoptotic effect in Fas-induced cell death. Proc Natl Acad Sci USA 2001; 98: 8662-8667.

6. Verhagen AM, Ekert PG, Pakusch M, Silke J, Connolly LM, Reid GE et al. Identification of DIABLO, a mammalian protein that promotes apoptosis by binding to and antagonizing IAP proteins. Cell 2000; 102: 43-53.

7. Du C, Fang M, Li Y, Li L, Wang X. Smac, a mitochondrial protein that promotes cytochrome c-dependent caspase activation by eliminating IAP inhibition. Cell 2000; 102: 33-42.

8. Martins LM, laccarino I, Tenev T, Gschmeissner S, Totty NF, Lemoine NR et al. The serine protease $\mathrm{Omi} / \mathrm{HtrA} 2$ regulates apoptosis by binding XIAP through a reaper-like motif. J Biol Chem 2002; 277: 439-444.

9. Hay BA. Understanding IAP function and regulation: a view from Drosophila. Cell Death Differ 2000; 7: 1045-1056.

10. Arama E, Agapite J, Steller H. Caspase activity and a specific cytochrome $\mathrm{C}$ are required for sperm differentiation in Drosophila. Dev Cell 2003; 4: 687-697.

11. Huh JR, Vernooy SY, Yu H, Yan N, Shi Y, Guo M et al. Multiple apoptotic caspase cascades are required in nonapoptotic roles for Drosophila spermatid individualization. PLoS Biol 2004; 2: e15.

12. Pérez-Garijo A, Martín FA, Morata G. Caspase inhibition during apoptosis causes abnormal signalling and developmental aberrations in Drosophila. Development 2004; 131: 5591-5598.

13. Hu JR, Guo M, Hay BA. Compensatory proliferation induced by cell death in the Drosophila wing disc requires activity of the apical cell death caspase Dronc in a nonapoptotic role. Curr Biol 2004; 14: 1262-1266.

14. Ryoo HD, Gorenc T, Steller H. Apoptotic cells can induce compensatory cell proliferation through the JNK and the wingless signaling pathways. Dev Cell 2004; 7: 491-501.

15. Kondo S, Senoo-Matsuda N, Hiromi Y, Miura M. DRONC coordinates cell death and compensatory proliferation. Mol Cell Biol 2006; 26: 7258-7268.

16. Wells BS, Yoshida E, Johnston LA. Compensatory proliferation in Drosophila imaginal discs requires Dronc-dependent p53 activity. Curr Biol 2006; 16: 1606-1615.

17. Kanuka H, Kuranaga E, Takemoto K, Hiratou T, Okano H, Miura M. Drosophila caspase transduces Shaggy/GSK-3beta kinase activity in neural precursor development. EMBO J 2005; 24: 3793-3806.

18. Campbell DS, Holt CE. Apoptotic pathway and MAPKs differentially regulate chemotropic responses of retinal growth cones. Neuron 2003; 37: 939-952.
19. Kuranaga $E$, Miura M. Nonapoptotic functions of caspases: caspases as regulatory molecules for immunity and cell-fate determination. Trends Cell Biol 2007; 17: 135-144.

20. Yaron A, Schuldiner O. Common and divergent mechanisms in developmental neuronal remodeling and dying back neurodegeneration. Curr Biol 2016; 26: R628-R639.

21. Penzes P, Cahill ME, Jones KA, Van Leeuwen JE, Woolfrey KM. Dendritic spine pathology in neuropsychiatric disorders. Nat Neurosci 2011; 14: 285-293.

22. Hutsler JJ, Zhang H. Increased dendritic spine densities on cortical projection neurons in autism spectrum disorders. Brain Res 2010; 130: 83-94.

23. Walsh MK, Lichtman JW. In vivo time-lapse imaging of synaptic takeover associated with naturally occurring synapse elimination. Neuron 2003; 37: 67-73.

24. Bishop DL, Misgeld T, Walsh MK, Gan WB, Lichtman JW. Axon branch removal at developing synapses by axosome shedding. Neuron 2004; 44: 651-661.

25. Riccomagno MM, Kolodkin AL. Sculpting neural circuits by axon and dendrite pruning. Ann Rev Cell Dev Biol 2015; 31: 779-805.

26. Okamoto K, Nagai T, Miyawaki A, Hayashi Y. Rapid and persistent modulation of actin dynamics regulates postsynaptic reorganization underlying bidirectional plasticity. Nat Neurosci 2004; 7: 1104-1112.

27. Zhou Q, Homma KJ, Poo MM. Shrinkage of dendritic spines associated with long-term depression of hippocampal synapses. Neuron 2004; 44: 749-757.

28. Truman JW, Reiss SE. Dendritic reorganization of an identified motoneuron during metamorphosis of the tobacco hornworm moth. Science 1976; 192: 477-479.

29. Lee T, Marticke S, Sung C, Robinow S, Luo L. Cell-autonomous requirement of the USP EcR-B ecdysone receptor for mushroom body neuronal remodeling in Drosophila. Neuron 2000; 28: 807-818.

30. Schubiger M, Wade AA, Carney GE, Truman JW, Bender M. Drosophila EcR-B ecdysone receptor isoforms are required for larval molting and for neuron remodeling during metamorphosis. Development 1998; 125: 2053-2062.

31. Watts RJ, Hoopfer ED, Luo L. Axon pruning during Drosophila metamorphosis: evidence for local degeneration and requirement of the ubiquitin-proteasome system. Neuron 2003; 38: $871-885$

32. Nakamura $\mathrm{H}, \mathrm{O}$ 'Leary $\mathrm{DD}$. Inaccuracies in initial growth and arborization of chick retinotectal axons followed by course corrections and axon remodeling to develop topographic order. J Neurosci 1989; 9: 3776-3795.

33. Portera-Cailliau C, Weimer RM, De Paola V, Caroni P, Svoboda K. Diverse modes of axon elaboration in the developing neocortex. PLoS Biol 2005; 3: e272.

34. Williams DW, Truman JW. Cellular mechanisms of dendrite pruning in Drosophila: insights from in vivo time-lapse of remodeling dendritic arborizing sensory neurons. Development 2005; 132: 3631-3642.

35. Kuo CT, Jan LY, Jan YN. Dendrite-specific remodeling of Drosophila sensory neurons requires matrix metalloproteases, ubiquitin-proteasome, and ecdysone signaling. Proc Nat Acad Sci USA 2005; 102: 15230-15235.

36. Williams DW, Truman JW. Mechanisms of dendritic elaboration of sensory neurons in Drosophila: insights from in vivo time lapse. J Neurosci 2004; 24: 1541-1550.

37. Raff MC, Whitmore AV, Finn JT. Axonal self-destruction and neurodegeneration. Science 2002; 296: 868-871.

38. Sagot Y, Dubois-Dauphin M, Tan SA, de Bilbao F, Aebischer P, Martinou JC et al. Bcl-2 overexpression prevents motoneuron cell body loss but not axonal degeneration in a mouse model of a neurodegenerative disease. J Neurosci 1995; 15: 7727-7733.

39. Williams DW, Kondo S, Krzyzanowska A, Hiromi Y, Truman JW. Local caspase activity directs engulfment of dendrites during pruning. Nat Neurosci 2006; 9: 1234-1236.

40. Kuo CT, Zhu S, Younger S, Jan LY, Jan YN. Identification of E2/E3 ubiquitinating enzymes and caspase activity regulating Drosophila sensory neuron dendrite pruning. Neuron 2006; 51: 283-290.

41. Rumpf S, Lee SB, Jan LY, Jan YN. Neuronal remodeling and apoptosis require VCP-dependent degradation of the apoptosis inhibitor DIAP1. Development 2011; 138 1153-1160.

42. Ernsberger $\mathrm{U}$. Role of neurotrophin signalling in the differentiation of neurons from dorsal root ganglia and sympathetic ganglia. Cell Tissue Res 2009; 336: 349-384.

43. Nikolaev A, McLaughlin T, O'Leary DD, Tessier-Lavigne M. APP binds DR6 to trigger axon pruning and neuron death via distinct caspases. Nature 2009; 457: 981-989.

44. Simon DJ, Weimer RM, McLaughlin T, Kallop D, Stanger K, Yang J et al. A caspase cascade regulating developmental axon degeneration. J Neurosci 2012; 32: 17540-17553.

45. Cusack CL, Swahari V, Hampton Henley W, Michael Ramsey J, Deshmukh M. Distinct pathways mediate axon degeneration during apoptosis and axon-specific pruning Nat Commun 2013; 4: 1876

46. Unsain N, Higgins JM, Parker KN, Johnstone AD, Barker PA. XIAP regulates caspase activity in degenerating axons. Cell Rep 2013; 4: 751-763.

47. Simon DJ, Pitts J, Hertz NT, Yang J, Yamagishi Y, Olsen $\mathrm{O}$ et al. Axon degeneration gated by retrograde activation of somatic pro-apoptotic signaling. Cell 2016; 164: 1031-1045.

48. Bliss TV, Lomo T. Long-lasting potentiation of synaptic transmission in the dentate area of the anaesthetized rabbit following stimulation of the perforant path. J Physiol 1973; 232 331-356.

49. Dudek SM, Bear MF. Homosynaptic long-term depression in area CA1 of hippocampus and effects of N-methyl-D-aspartate receptor blockade. Proc Natl Acad Sci USA 1992; 89 4363-4367.

50. Mulkey RM, Malenka RC. Mechanisms underlying induction of homosynaptic long-term depression in area CA1 of the hippocampus. Neuron 1992; 9: 967-975. 
51. Bliss TV, Collingridge GL. A synaptic model of memory: long-term potentiation in the hippocampus. Nature 1993; 361: 31-39.

52. Sheng M, Ertürk A. Long-term depression: a cell biological view. Philos Trans $R$ Soc Lond $B$ Biol Sci 2013; 369: 20130138

53. Lendvai B, Stern EA, Chen B, Svoboda K. Experience-dependent plasticity of dendritic spines in the developing rat barrel cortex in vivo. Nature 2000; 404: 876-881.

54. Lee HK, Kameyama K, Huganir RL, Bear MF. NMDA induces long-term synaptic depression and dephosphorylation of the GluR1 subunit of AMPA receptors in hippocampus. Neuron 1998; 21: 1151-1162.

55. Oh WC, Hill TC, Zito K. Synapse-specific and size-dependent mechanisms of spine structural plasticity accompanying synaptic weakening. Proc Natl Acad Sci USA 2013; 110: E305-E312.

56. Mattson MP, Keller JN, Begley JG. Evidence for synaptic apoptosis. Exp Neurol 1998; 153 35-48.

57. Mattson MP, Duan W. 'Apoptotic' biochemical cascades in synaptic compartments: roles in adaptive plasticity and neurodegenerative disorders. J Neurosci Res 1999; 58 152-166.

58. Lu C, Fu W, Salvesen GS, Mattson MP. Direct cleavage of AMPA receptor subunit GluR1 and suppression of AMPA currents by caspase-3: implications for synaptic plasticity and excitotoxic neuronal death. Neuromolecular Med 2002; 1: 69-79.

59. Dash PK, Blum S, Moore AN. Caspase activity plays an essential role in long-term memory. Neuroreport 2000; 11: 2811-2816.

60. Stepanichev MY, Kudryashova IV, Yakovlev AA, Onufriev MV, Khaspekov LG, Lyzhin AA et al. Central administration of a caspase inhibitor impairs shuttle-box performance in rats. Neuroscience 2005; 136: 579-591.

61. Gulyaeva NV, Kudryashov IE, Kudryashova IV. Caspase activity is essential for long-term potentiation. J Neurosci Res 2003; 73: 853-864.

62. Li Z, Jo J, Jia JM, Lo SC, Whitcomb DJ, Jiao S et al. Caspase-3 activation via mitochondria is required for long-term depression and AMPA receptor internalization. Cell 2010; 141 859-871.

63. Huesmann GR, Clayton DF. Dynamic role of postsynaptic caspase-3 and BIRC4 in Zebra finch song response habituation. Neuron 2006; 52: 1061-1072.

64. Gibon J, Unsain N, Gamache K, Thomas RA, De Leon A, Johnstone A et al. The X-linked inhibitor of apoptosis regulates long-term depression and learning rate. FASEB J 2016; 30 3083-3090.

65. Jiao S, Li Z. Nonapoptotic function of BAD and BAX in long-term depression of synaptic transmission. Neuron 2011; 70: 758-772.

66. Liu X, Gu QH, Duan K, Li Z. NMDA receptor-dependent LTD is required for consolidation but not acquisition of fear memory. J Neurosci 2014; 34: 8741-8748.

67. Dorostkar MM, Zou C, Blazquez-Llorca L, Herms J. Analyzing dendritic spine pathology in Alzheimer's disease: problems and opportunities. Acta Neuropathol 2015; 130 $1-19$.

68. de Calignon A, Spires-Jones TL, Pitstick R, Carlson GA, Hyman BT. Tangle-bearing neurons survive despite disruption of membrane integrity in a mouse model of tauopathy. J Neuropathol Exp Neurol 2009; 68: 757-761.

69. de Calignon A, Fox LM, Pitstick R, Carlson GA, Bacskai BJ, Spires-Jones TL, Hyman BT. Caspase activation precedes and leads to tangles. Nature 2010; 464: 1201-1204

70. D'Amelio M, Cavallucci V, Middei S, Marchetti C, Pacioni S, Ferri A et al. Caspase-3 triggers early synaptic dysfunction in a mouse model of Alzheimer's disease. Nat Neurosci 2011; 14: 69-76.

71. Bredesen DE. Neurodegeneration in Alzheimer's disease: caspases and synaptic element interdependence. Mol Neurodegener 2009; 4: 27.

72. Snyder EM, Nong Y, Almeida CG, Paul S, Moran T, Choi EY et al. Regulation of NMDA receptor trafficking by amyloid-beta. Nat Neurosci 2005; 8: 1051-1058.

73. Parsons MP, Raymond LA. Extrasynaptic NMDA receptor involvement in central nervous system disorders. Neuron 2014; 82: 279-293.

74. Jo J, Whitcomb DJ, Olsen KM, Kerrigan TL, Lo SC, Bru-Mercier G et al. A $\beta(1-42)$ inhibition of LTP is mediated by a signaling pathway involving caspase-3, Akt1 and GSK-3beta. Na Neurosci 2011: 14: 545-547.

75. Puzzo D, Privitera L, Leznik E, Fà M, Staniszewski A, Palmeri A, Arancio O. Picomola amyloid-beta positively modulates synaptic plasticity and memory in hippocampus. Jeurosci 2008; 28: 14537-14545.

76. Garcia-Osta A, Alberini CM. Amyloid beta mediates memory formation. Learn Mem 2009 16: 267-272.

77. Albrecht S, Bourdeau M, Bennett D, Mufson EJ, Bhattacharjee M, LeBlanc AC. Activation of caspase-6 in aging and mild cognitive impairment. Am J Pathol 2007; 170: 1200-1209.

78. Hitomi J, Katayama T, Eguchi Y, Kudo T, Taniguchi M, Koyama $Y$ et al. Involvement of caspase- 4 in endoplasmic reticulum stress-induced apoptosis and Abeta-induced cell death. J Cell Biol 2004; 165: 347-356.

79. Lee JH, Won SM, Suh J, Son SJ, Moon GJ, Park UJ et al. Induction of the unfolded protein response and cell death pathway in Alzheimer's disease, but not in aged Tg2576 mice. Exp Mol Med 2010; 42: 386-394.

80. Prasanthi JR, Larson T, Schommer J, Ghribi O. Silencing GADD153/CHOP gene expression protects against Alzheimer's disease-like pathology induced by 27-hydroxycholesterol in rabbit hippocampus. PLOS ONE 2011; 6: e26420.

81. Klaiman G, Petzke TL, Hammond J, Leblanc AC. Targets of caspase-6 activity in human neurons and Alzheimer disease. Mol Cell Proteomics 2008; 7: 1541-1555.
82. Park SA, Shaked GM, Bredesen DE, Koo EH. Mechanism of cytotoxicity mediated by the C31 fragment of the amyloid precursor protein. Biochem Biophys Res Commun 2009; 388 : 450-455.

83. Lu DC, Rabizadeh S, Chandra S, Shayya RF, Ellerby LM, Ye X et al. A second cytotoxic proteolytic peptide derived from amyloid beta-protein precursor. Nat Med 2000; 6: 397-404.

84. Hell K, Saleh M, Crescenzo GD, O'Connor-McCourt MD, Nicholson DW. Substrate cleavage by caspases generates protein fragments with Smac/Diablo-like activities. Cell Death Differ 2003; 10: 1234-1239.

85. Kuchibhotla KV, Goldman ST, Lattarulo CR, Wu HY, Hyman BT, Bacskai BJ. Abeta plaques lead to aberrant regulation of calcium homeostasis in vivo resulting in structural and functional disruption of neuronal networks. Neuron 2008; 59: 214-225.

86. Fasulo L, Ugolini G, Visintin M, Bradbury A, Brancolini C, Verzillo V et al. The neuronal microtubule associated protein tau is a substrate for caspase-3 and an effector of apoptosis. $J$ Neurochem 2000; 75: 624-633.

87. Wang XJ, Cao Q, Zhang Y, Su XD. Activation and regulation of caspase- 6 and its role in neurodegenerative diseases. Annu Rev Pharmacol Toxicol 2014; 55: 553-572.

88. Wellington CL, Ellerby LM, Hackam AS, Margolis RL, Trifiro MA, Singaraja R et al. Caspase cleavage of gene products associated with triplet expansion disorders generates truncated fragments containing the polyglutamine tract. J Biol Chem 1998; 273: 9158-9167.

89. Wellington CL, Singaraja R, Ellerby L, Savill J, Roy S, Leavitt B et al. Inhibiting caspase cleavage of huntingtin reduces toxicity and aggregate formation in neuronal and nonneuronal cells. J Biol Chem 2000; 275: 19831-19838.

90. Warby SC, Doty CN, Graham RK, Carroll JB, Yang YZ, Singaraja RR et al. Activated caspase- 6 and caspase- 6 cleaved fragments of huntingtin specifically colocalize in the nucleus. Hum Mol Genet 2008; 17: 2390-2404.

91. Li SH, Lam S, Cheng AL, Li XJ. Intranuclear huntingtin increases the expression of caspase-1 and induces apoptosis. Hum Mol Genet 2000; 19: 2859-2867.

92. Orth M, Handley OJ, Schwenke C, Dunnett SB, Craufurd D, Ho AK et al. Observing Huntington's disease: the European Huntington's Disease Network's REGISTRY. PLoS Curr 2010; ;2: RRN1184.

93. Usdin MT, Shelbourne PF, Myers RM, Madison DV. Impaired synaptic plasticity in mice carrying the Huntington's disease mutation. Hum Mol Genet 1999; 8: 839-846.

94. Murphy KP, Carter RJ, Lione LA, Mangiarini L, Mahal A, Bates GP et al. Abnormal synaptic plasticity and impaired spatial cognition in mice transgenic for exon 1 of the human Huntington's disease mutation. J Neurosci 2000; 20: 5115-5123.

95. Milnerwood AJ, Cummings DM, Dallérac GM, Brown JY, Vatsavayai SC, Hirst MC et al. Early development of aberrant synaptic plasticity in a mouse model of Huntington's disease. Hum Mol Genet 2006; 15: 1690-1703

96. Murmu RP, Li W, Li JY. B23 mutant huntingtin causes loss of mechanisms underlying long-term memory storage in the brain revealed by two-photon imaging. $J$ Neurol Neurosurg Psychiatry 2014; 85(Suppl 1): A17.

97. Rigamonti D, Bauer JH, De-Fraja C, Conti L, Sipione S, Sciorati C et al. Wild-type huntingtin protects from apoptosis upstream of caspase-3. J Neurosci 2000; 20: 3705-3713.

98. Zhang Y, Leavitt BR, van Raamsdonk JM, Dragatsis I, Goldowitz D, MacDonald ME et al. Huntingtin inhibits caspase-3 activation. EMBO J 2006; 25: 5896-5906.

99. Florentin A, Arama E. Caspase levels and execution efficiencies determine the apoptotic potential of the cell. J Cell Biol 2012; 196: 513-527.

100. Kirilly D, Gu Y, HuangY WuZ, Bashirullah A, Low BC et al. A genetic pathway composed of Sox14 and Mical governs severing of dendrites during pruning. Nat Neurosci 2009; 12: 1497-1505.

101. Cakouros D, Daish T, Martin D, Baehrecke EH, Kumar S. Ecdysone-induced expression of the caspase DRONC during hormone-dependent programmed cell death in Drosophila is regulated by Broad-Complex. J Cell Biol 2002; 157: 985-996.

102. Kilpatrick ZE, Cakouros D, Kumar S. Ecdysone-mediated up-regulation of the effector caspase DRICE is required for hormone-dependent apoptosis in Drosophila cells. J Biol Chem 2005; 280: 11981-11986.

103. Daish TJ, Cakouros D, Kumar S. Distinct promoter regions regulate spatial and temporal expression of the Drosophila caspase Dronc. Cell Death Differ 2003; 10: 1348-1356.

104. Lee TV, Fan Y, Wang S, Srivastava M, Broemer M, Meier P, Bergmann A. Drosophila IAP1mediated ubiquitylation controls activation of the initiator caspase DRONC independent of protein degradation. PLoS Genet 2011; 7: e1002261.

105. Kole AJ, Annis RP, Deshmukh M. Mature neurons: equipped for survival. Cell Death Dis 2013; 4: e689.

106. Wright KM, Smith MI, Farrag L, Deshmukh M. Chromatin modification of Apaf-1 restricts the apoptotic pathway in mature neurons. J Cell Biol 2007; 179: 825-832.

107. Pollack M, Phaneuf S, Dirks A, Leeuwenburgh C. The role of apoptosis in the normal aging brain, skeletal muscle, and heart. Ann NYAcad Sci 2002; 959: 93-107.

108. Shapiro PJ, Hsu HH, Jung H, Robbins ES, Ryoo HD. Regulation of the Drosophila apoptosome through feedback inhibition. Nat Cell Biol 2008; 10: 1440-1446.

109. Koerver L, Melzer J, Roca EA, Teichert D, Glatter T, Arama E, Broemer M. The de-ubiquitylating enzyme DUBA is essential for spermatogenesis in Drosophila. Cell Death Differ 2016; 23: 2019-2030.

110. Allan LA, Clarke PR. Apoptosis and autophagy: regulation of caspase-9 by phosphorylation. FEBS J 2009; 276: 6063-6073.

111. Deveraux QL, Takahashi R, Salvesen GS, Reed JC. X-linked IAP is a direct inhibitor of cell-death proteases. Nature 1997; 388: 300-304. 
112. Burke SP, Smith L, Smith JB. clAP1 cooperatively inhibits procaspase-3 activation by the caspase-9 apoptosome. J Biol Chem 2010; 285: 30061-30068.

113. Huang Y, Rich RL, Myszka DG, Wu H. Requirement of both the second and third BIR domains for the relief of $X$-linked inhibitor of apoptosis protein (XIAP)-mediated caspase inhibition by Smac. J Biol Chem 2003; 278: 49517-49522.

114. Takahashi R, Deveraux Q, Tamm I, Welsh K, Assa-Munt N, Salvesen GS, Reed JC. A single BIR domain of XIAP sufficient for inhibiting caspases. J Biol Chem 1998; 273: 7787-7790.

115. Springs SL, Diavolitsis VM, Goodhouse J, McLendon GL. The kinetics of translocation of Smac/DIABLO from the mitochondria to the cytosol in HeLa cells. J Biol Chem 2002; 277: 457150-457158

116. Madesh M, Antonsson B, Srinivasula SM, Alnemri ES, Hajnóczky G. Rapid kinetics of tBidinduced cytochrome $\mathrm{c}$ and Smac/DIABLO release and mitochondrial depolarization. J Biol Chem 2002; 277: 5651-5659.

117. Rehm M, Düßmann H, Prehn JH. Real-time single cell analysis of Smac/DIABLO release during apoptosis. J Cell Biol 2003; 162: 1031-1043.

118. Moubarak RS, Planells-Ferrer L, Urresti J, Reix S, Segura MF, Carriba P et al. FAIM-L is an IAP-binding protein that inhibits XIAP ubiquitinylation and protects from Fas-induced apoptosis. J Neurosci 2013; 33: 19262-19275.

119. Segura MF, Sole C, Pascual M, Moubarak RS, Perez-Garcia MJ, Gozzelino R et al. The long form of Fas apoptotic inhibitory molecule is expressed specifically in neurons and protects them against death receptor-triggered apoptosis. J Neurosci 2007; 27: 11228-11241.

120. Martínez-Mármol R, Barneda-Zahonero B, Soto D, Andrés RM, Coccia E, Gasull X et al. FAIM-L regulation of XIAP degradation modulates synaptic long-term depression and axon degeneration. Sci Rep 2016; 6: 35775.

121. de Botton S, Sabri S, Daugas E, Zermati Y, Guidotti JE, Hermine $O$ et al. Platelet formation is the consequence of caspase activation within megakaryocytes. Blood 2002; 100: 1310-1317.

122. MacFarlane M, MerrisonW, Dinsdale D, Cohen GM. Active caspases and cleaved cytokeratins are sequestered into cytoplasmic inclusions in TRAIL-induced apoptosis. J Cell Biol 2000; 148: 1239-1254.

123. van Loo G, Saelens X, Matthijssens F, Schotte P, Beyaert R, Declercq W, Vandenabeele P. Caspases are not localized in mitochondria during life or death. Cell Death Differ 2002; 9: 1207-1211.

124. Li Z, Okamoto KI, Hayashi Y, Sheng M. The importance of dendritic mitochondria in the morphogenesis and plasticity of spines and synapses. Cell 2004; 119: 873-887.

125. Nishiyama M, Hong K, Mikoshiba K, Poo MM, Kato K. Calcium stores regulate the polarity and input specificity of synaptic modification. Nature 2000; 408: 584-588.

126. Ertürk A, Wang $Y$, Sheng M. Local pruning of dendrites and spines by caspase-3dependent and proteasome-limited mechanisms. J Neurosci 2014; 34: 1672-1688.
127. Steinhauer J. Separating from the pack: molecular mechanisms of Drosophila spermatid individualization. Spermatogenesis 2015; 5: e1041345.

128. D'Brot A, Chen P, Vaishnav M, Yuan S, Akey CW, Abrams JM. Tango7 directs cellular remodeling by the Drosophila apoptosome. Genes Dev 2013; 27: 1650-1655.

129. Fischer U, Jänicke RU, Schulze-Osthoff K. Many cuts to ruin: a comprehensive update of caspase substrates. Cell Death Differ 2003; 10: 76-100.

130. Sokolowski JD, Gamage KK, Heffron DS, LeBlanc AC, Deppmann CD, Mandell JW. Caspase-mediated cleavage of actin and tubulin is a common feature and sensitive marker of axonal degeneration in neural development and injury. Acta Neuropathol Commun 2014 2: 16

131. Campbell DS, Okamoto $\mathrm{H}$. Local caspase activation interacts with Slit-Robo signaling to restrict axonal arborisation. J Cell Biol 2013; 203: 657-672.

132. Los M, Stroh C, Jänicke RU, Engels IH, Schulze-Osthoff K. Caspases: more than jus killers? Trends Immunol 2001; 22: 31-34.

133. Mack TG, Reiner M, Beirowski B, Mi W, Emanuelli M, Wagner D et al. Wallerian degeneration of injured axons and synapses is delayed by a Ube4b/Nmnat chimeric gene. Nature Neurosci 2001; 4: 1199-1206.

134. Coleman MP, Freeman MR. Wallerian degeneration, wld(s), and nmnat. Annu Rev Neurosci 2010; 33: 245-267.

135. Osterloh JM, Yang J, Rooney TM, Fox AN, Adalbert R, Powell EH et al. dSarm/Sarm1 is required for activation of an injury-induced axon death pathway. Science 2012; 337: 481-484.

136. Schoenmann Z, Assa-Kunik E, Tiomny S, Minis A, Haklai-Topper L, Arama E, Yaron A. Axonal degeneration is regulated by the apoptotic machinery or a NAD+-sensitive pathway in insects and mammals. J Neurosci 2010; 30: 6375-6386.

(c) (i) This work is licensed under a Creative Commons Attribution 4.0 International License. The images or other third party material in this article are included in the article's Creative Commons license, unless indicated otherwise in the credit line; if the material is not included under the Creative Commons license, users will need to obtain permission from the license holder to reproduce the material. To view a copy of this license, visit http:// creativecommons.org/licenses/by/4.0/

C) The Author(s) 2017 